\title{
ЛИНЕЙНАЯ АНТЕННАЯ РЕШЕТКА КВЧ ДИАПАЗОНА НА ОСНОВЕ ПРЕОБРАЗОВАНИЯ ПОВЕРХНОСТНЫХ ВОЛН
}

\author{
А. В. ГНАТОВСКИЙ, С. А. ПРОВАЛОВ, Г. И. ХЛОПОВ \\ Институт радиофизики и электроники Национальной Академии наук Украины, \\ Украина, Харьков, 61085, ул. Проскуры 12
}

\begin{abstract}
Аннотация. Опыт применения экспериментальных образцов антенн дифракционного излучения указывает на необходимость расширения перечня вариантов и модификаций технических решений таких антенн. Одним из вариантов таких решений является модификация линейного диэлектрического волновода с целью жесткой фиксации диэлектрического стержня. В данной работе предложено использовать Н-образные волноводы поверхностных волн в виде сочетания диэлектрического стержня и металлических элементов в качестве базовых элементов антенн дифракционного излучения, предназначенных для работы в условиях повышенных механических нагрузок и вибраций на частотах выше 80 ГГц. Представлены результаты экспериментальных исследований распределения ближних полей в раскрыве, диаграммы направленности, коэффициента усиления и потерь энергии в антенне, характеризующие эффективность реализованного конструктивного подхода. Предложена конфигурация антенной линейной решетки дифракционного излучения с модифицированным диэлектрическим волноводом, что является основой для разработки сканирующих антенн в диапазоне свыше 80-100 ГГц.
\end{abstract}

Ключевые слова: антенная решетка; Н-образный металлодиэлектрический волновод; распределение ближнего поля; диаграмма направленности

\section{ВВЕДЕНИЕ}

Развитие средств коммуникации, навигации, радиолокации, мониторинга окружающего пространства обеспечивается за счет освоения все более коротковолновых диапазонов электромагнитных волн. Для этого помимо модернизации существующих радиоустройств необходимо создание принципиально новых технических образцов, например антенн дифракционного излучения.

В разработке антенных систем выделилось направление, связанное с применением линейных, плоскостных и конформных фазированных антенных решеток [1]. Как правило, сложные двумерные решетки создаются из линейных решеток, расположенных на заданной поверхности. Поэтому всегда существует интерес разработчиков антенных систем к теоретическим и экспериментальным исследованиям линейных решеток.

Традиционно в линейных решетках дециметрового и сантиметрового диапазонов в качестве излучателей используют вибраторы и щелевые излучатели, а также рупорные антенны, возбуждение которых реализуется по схеме последовательного или параллельного питания с использованием большого количества управляемых элементов волноводного тракта.

Однако реализация подобных систем в миллиметровом диапазоне длин волн (ММД), и, особенно, в его коротковолновой части (КВЧ), с использованием полых металлических волноводов или полосковых линий раз- 


\section{БИБЛИОГРАФИЧЕСКИЙ СПИСОК}

1. Антенны и устройства СВЧ. Под ред. Д. И. Воскресенского. М.: Радио и связь, 1981. 432 с.

2. Андренко, С.Д.; Сидоренко, Ю.Б.; Шестопалов, В.П. "К вопросу о преобразовании поверхностных волн в объемные,” ДАН УССР, № 12, С. 156-159, 1976.

3. Андренко, С. Д.; Девятков, Н.Д.; Шестопалов, В.П. "Антенные решетки миллиметрового диапазона,” ДАН СССР, Т. 240, № 6, С. 1340-1343, 1978.

4. Sautbekov, S.; Sirenko, K.; Sirenko, Yu.; Yevdokymov, A. "Diffraction radiation effects: a theoretical and experimental study," IEEE Antennas Propag. Mag., Vol. 57, No. 5, p. 73-93, 2015. DOI: $\underline{10.1109 /}$ MAP.2015.2470673.

5. Kusaykin, O. P.; Melezhik, P. N.; Poyedinchuk, A. E.; Provalov, S. A.; Seleznyov, D. G. "Surface and leaky waves of a planar dielectric waveguide with a diffraction grating," IET Microwaves, Antennas \& Propag., Vol. 10, No. 1, p. 61-67, 2016. DOI: 10.1049/iet-map.2015.0158.

6. Кириленко, А.А.; Стешенко, С.А. "Строгая двумерная модель эффекта преобразования поверхностных волн в объемные," Радиофизика и электроника, T. 10, № 1, C. 30-38, 2005.

7. Мележик, П.Н.; Разсказовский, В.Б.; Резниченко, Н.Г.; Зуйков, В.А.; Андренко, С.Д.; Сидоренко, Ю.В.; Провалов, С.А.; Варавин, А.В.; Усов, Л.С.; Чмиль, В.М.; Муськин, Ю.Н. "Полупроводниковый когерентный радиолокатор миллиметрового диапазона для контроля наземного движения в аэропортах," Наука та інновації, Т. 4, № 3, С. 5-13, 2008. DOI: $10.15407 / \mathrm{scin} 4.03 .005$.

8. Петр Николаевич Мележик, Юрий Борисович Сидоренко, Сергей Анатольевич Провалов, Станислав Дмитриевич Андренко, Сергей Анатольевич Шило. "Плоскостная антенна дифракционного излучения радиолокационного комплекса миллиметрового диапазона," Известия вузов. Радиоэлектроника, Т. 53, № 5, C. 12-21, 2010. URI: http://radio.kpi.ua/article/view/S00 2134701005002X.

9. Гнатовский, А. В.; Провалов, С. А. “Исследование свойств комбинированных решеток в антеннах дифракционного излучения," Радиофизика и электроника, T. 5, № 2. C. 10-15, 2014. URI: http://nbuv.gov.ua/ UJRN/rphre 2014 5\% 2819\%29 2 _ 4

10. Vertiy, A. A.; Sirenko, Yu. K.; Pavlyuchenko, A.; Poyedinchuk, A.; Sabyrov, A.; Sautbekov, S. S.; Yashina, N. P. "Surface-to-spatial mode conversion by a convex cylindrical diffraction grating: an experimental study," Telecom. Radio Eng., Vol. 75, No. 4, p. 297-311, 2016. DOI: 10.1615/TelecomRadEng.v75.i4.20.

11. Burambayeva, N.; Naumenko, V.; Sautbekov, S. S.; Sirenko, Yu. K.; Vertiy, A. A. "Modeling and analysis of a fast-scanning diffraction radiation antenna," Telecom. Radio Eng., Vol. 75, No. 3, p. 189-199, 2016. DOI: 10.1615/TelecomRadEng.v75.i3.10.

12. Cohn, M. "Propagation in a dielectric-loaded parallel plane waveguide," IRE Trans. Microwave Theory 
Tech., Vol. 7, No. 2, p. 202-208, 1959. DOI: 10.1109/ TMTT.1959.1124682.

13. Sanchez, A.; Oliner, A. A. "A new leaky waveguide for millimeter waves using nonradiative dielectric (NRD) waveguide - Part I: Accurate theory," IEEE Trans. Microwave Theory Tech., Vol. 35, No. 8, p. 737-747, 1987. DOI: 10.1109/TMTT.1987.1133740.

14. Qing, H.; Oliner, A. A.; Sanchez, A. "A new leaky waveguide for millimeter waves using nonradiative dielectric (NRD) waveguide - Part II: Comparison with experiments," IEEE Trans. Microwave Theory Tech., Vol. 35, No. 8, p. 748-752, 1987. DOI: 10.1109/TMTT.1987. 1133741.

15. Attari, J.; Boutayeb, H.; Wu, K. "A simplified implementation of substrate integrated non-radiative dielectric waveguide at millimeter-wave frequencies," PIER C, Vol. 55, p. 83-94, 2014. DOI: 10.2528/PIERC1 4051905.

16. Latrach, L.; Rihem, N.; Hanen, H.; Gharsallah, A. "Parametric and comparative studies of leaky wave image NRDG antenna designed with the ordinary single-layer and the double-layers rectangular image NRD guide," Int. J. Commun. Antenna Propag., Vol. 6, No. 2, p. 108-110, 2016. DOI: 10.15866/irecap.v6i2.8325.

17. Гутцайт, Э.М. “Типы волн в Н-образном металлодиэлектрическом волноводе," Радиотехника $u$ электроника, № 2, С. 310-320, 1962.

18. Шестопалов, В.П.; Литвиненко, Л.Н.; Масалов, С.А.; Сологуб, В.Г. Дифракиия волн на решетках. Харьков: Изд-во Харьк. ун-та, 1973. 273 с. 